\title{
Computer Students Attitudes on the Integration of m-Learning Applications
}

\author{
Abdulmohsin S. Alkhunaizan ${ }^{1}$ \\ Department of Information Systems, College of Computer and Information Sciences \\ Majmaah University, Majmaah 11952, Saudi Arabia
}

\begin{abstract}
Technology has an important role in the lives particularly in the field of education nowadays because of its accessibility and affordability. Mobile learning (m-Learning) which is form of e-learning is a novel approach in the arena of educational technology that offers personal, informal, blended learning and flexible learning opportunities to learners and instructors. The present study is an attempt to determine the computer students' attitudes on the integration of m-Learning app (WhatsApp). A total numbers of 143 student participants participated in the experiment. The study used quasiexperimental research design. The learners were performed intact groups of a public university. They were asked to complete the assignments through WhatsApp application. Two questionnaires were used to gather the data. The data was analyzed descriptively. Findings of the data showed that learners had positive attitudes towards the integration of $\mathrm{m}$-Learning apps. The study also reports the suggestions for the future research and implications for the teachers.
\end{abstract}

Keywords-e-Learning; m-Learning; mobile applications; computer science; WhatsApp

\section{INTRODUCTION}

21 st century has derived the mode of e-Leaning to mLearning. Mobile phones are being replaced with computers. There is a transition from Computer Assisted Instruction [1] to Mobile Assisted Instruction (MAI) Smartphones have gained the popularity in the teaching instructions and these have gained an important position in the daily life particularly for learning purposes. The key reason behind this notion is that these gadgets are the source of gateway for global interaction. Because of the rapid progression and innovation, the use of computer technology is persistently used in education institutions [2]. Now the teachers have access to computer labs in the shape of mobile learning ubiquitously. The importance of computer and mobile technology has become so important and increasingly utilized in classroom. Thus, its importance cannot be ignored for the computer science students.

The modern classrooms are now equipped with flipped classes, computer labs and integrated learning around the globe [3]. Most of the educational institutions require a model that facilitates its teaching and academic faculty with the necessities to develop the learning process and better involvement of the blended learning. These higher educational institutions incorporate e-Learning in the shape Web-based teaching (WBT), virtual learning (VL) and learning management system (LMS) or some other e-Learning apps and educational technologies for various types of teaching and learning process [4]. Educational technology offers a valuable assistance to learners to make learning process easy and understandable in its capacity. The schools are persistently in state of doubt by increased availability, presence, ubiquity, and role of educational technology in classroom setting.

The use of technology greatly relies on the teachers, students and in particular educational institutions' environments. Numerous studies [3, 5, 6] have recommended that the incorporation of technology can foster the learning abilities, develop motivation and aid overall learning efficiently. The integration of E-learning and ICT courses with the formal discourse requires the key skills those could be evaluated, measured and shifted from teachers to students; teacher to teachers and other academic professional for its effective transformation. These skills can develop the use and integration of E- learning more effectively and naturally. Moreover, this will lead to the development of the performance of various learning pursuits as compared to bizarre integration of computers or mobile phones with the formal classroom.

E-Learning is also marked as the process of learning by the use of electronic means and developed online learning sources which present material with the assistance of computer, tabs and mobile phones [7]. The success of E-learning is quite optimal for the computer education as the basic need of the learner is the access to material and educational software and applications. The access to learning material is just one click away from the learners as instructors just need to upload the material and learners can download it anywhere. The fact is that nowadays online learning has replaced the formal classroom rooms and distance learning which are also cost effective for many different types of learners [8]. The progression of information technology (IT), Computers, global communication and present teaching environment stimulate the integration of E-learning. Several fields of education are equipped with these sorts of IT inventions and are envisioned for, teaching, training, research and innovations purposes and for educational consultancy as well. Furthermore, the support and planning for academic institutions to develop the capacity of e-Learning also requires the key developments and innovations of the apps and the environment of the institution [9].

\section{M-LEARNING}

From the last few years, instructors and institutions have been supporting instructive paradigms that encourage formal and well-balanced learning. The teaching material and work is retained for the concerned people who administer the 
presentation of knowledge and information to the learners in these paradigms. Presently, the concentration in higher studies has shifted from the concept of instruction to blended learning that fosters the process of learning. The universities are using m-Learning apps to deliver the instruction for communication and teaching. The norm of teaching has started on focusing on paradigm shift instead of skills and capacities and institutions are analyzing the capabilities of learning applications [10]. The integration of smartphones is one of the key aspects of the educational transition. Mobile phones have directed a developed learning method, which is now in every learner's hand, and it is operative to use for educational purposes. The smartphones phones have the capacity of connectivity and dynamic methods of teaching and presenting material as well as information.

By evoking, the notion of "m-Learning" the individual contemplates impulsively about the prospect of learning beyond the fixed or predetermined environment [11]. It would be better to argue that m-Learning is not mere operation of mobile or smartphone devices in an e-learning field, but an expedient function of a dynamic and intricate process of learning [12]. To attain the full benefits of m-Learning, the knowledge of its innovation is essential. This needs stepping further than the apparent definition, concept definition and observing the proficiencies of smartphone devices and the background in which the students gain access to the learning material and instruction [13]. It is a re-evaluating of learning that stem from the learners' perspective. Referring to this notion, m-Learning is an addition of e-learning. In general, elearning implies to a learning and instruction accompanied with various types of electronic tools and gadgets. In the eleaning instruction, there is always a variance in learning process between the applications and learning process. Even though electronic apparatus are utilized in m-Learning, the application and the learning as a whole, take place simultaneously. The primary purpose is to provide the important information and instruction in a precise time. $\mathrm{m}$ Learning offers an opportunity to a rapid and relevant and important material and instruction for the particular task to be achieved to the learners.

m-Learning can be interrupted from different aspects to different context and people. Apparently, it seems from beyond the formal learning with mobile gadgets such as tablets, laptops, smartphones and Mp3 players. Without any doubt these devices are necessary for the mobile phone-based learning and instruction. Broadly mentioning m-Learning is not more than only a device to attain the access to material, content and collaboration for the learning purposes as well as it is around the mobility of the learning process and learners. The author in [14] marked mobile learning as "the processes (both personal and public) of coming to know through exploration and conversation across multiple contexts amongst people and interactive technologies". In this regard, he further added that the key point in the arena of m-Learning is the context. m-Learning offers a clear and understandable context for the learning and instruction that is impracticable with the desktops and other computing devices [15]. m-Learning is better illustrated as the ubiquitous learning that involves the use of wireless network, handheld mobile devices and support that extend and enhance the hold of learning and instruction.
Educational organization both desire social revolution and have to act on it. In the view of GSMA (2011) an assessment conducted by Blackboard realized that "virtually all students own a mobile phone or smartphone." In reality, GSMA refers to statistics from Ofcom indicating, "99\% of people aged between 15 and 24 have a mobile phone, the highest penetration rate for any age group." Whereas, in 2000 the presence of mobile phone ownership was restricted to few people in the world and this was the problem for social connectivity that time. This conversion of "societal notions of discourse and knowledge" [16] is the milieu which institutions should both realize and control to stay relevant.

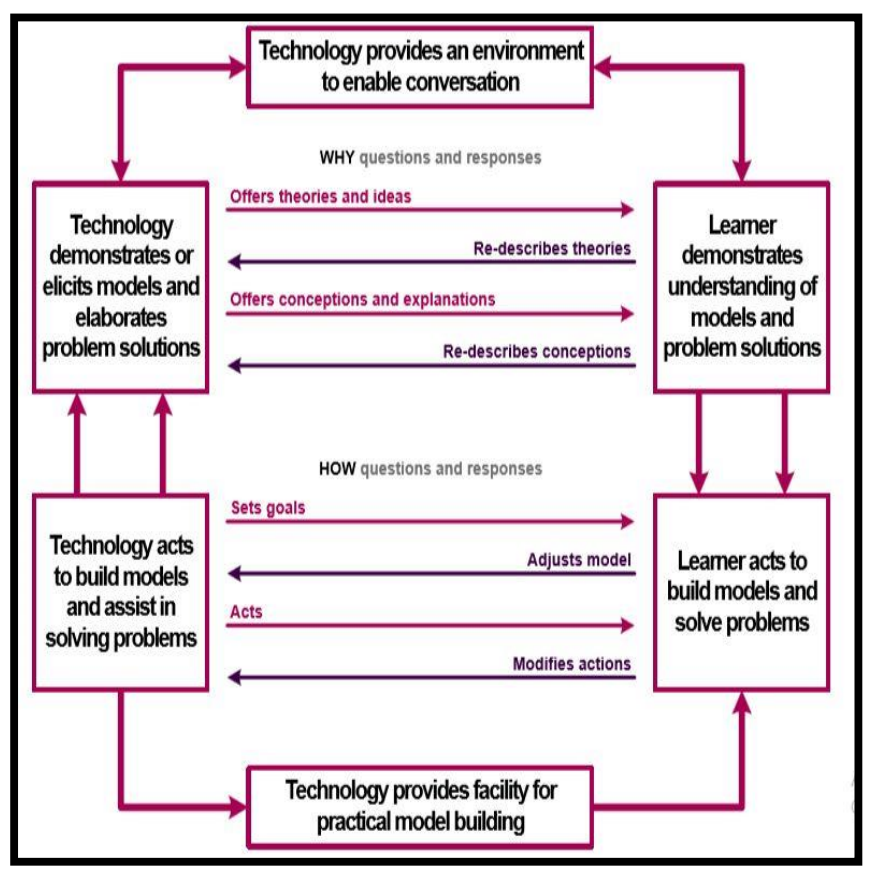

Fig. 1. Development Model of M-Learning [17]

Effective use of conversational Technology: Adopted from [17]

The essential functions of m-technology in developing the 'conversational learning' supported by Laurillard are as follows:

- offering a background and setting to assist conversation

- allowing learners to develop models with intentions of solving problems

This model includes both m-Learning and e-learning that allows the effective learning with the assistance of mobile devices, computer gadgets and applications.

\section{LITERATURE REVIEW}

Numerous researchers have put their attention on $\mathrm{m}$ Learning and its background recently. The literature is expanding on the notion of integration of m-Learning. An immediate search for the mobile application stores presents hundreds of free downloadable applications that can be used for learning and teaching. Nevertheless, m-Learning has the possibility to aid task-based learning and collaborative learning $[2,3,5,18,19]$ the importance dedicated in $\mathrm{m}$ - 
Learning has been primarily on the delivery of the content that followed teacher mediated technology integration. Early research focused on the sending SMS for quizzes, vocabulary, instruction receiving, and few have focused on the content and its incorporation for teaching.

The advantages of m-Learning apps are being investigated in different learning perceptive. The author in [20] carried out a study to develop learners' experiences and performance of the use of multimedia design. The researcher used numerous mobile phone apps for presentation and feedback session from the learners. The findings endorsed that the m-Learning is operative and successful for the participants and they enjoyed the m-Learning integration. Likewise, the study of [21] focused the mobile based application of Blackboard. The researchers used the mobile based application and desktopbased Blackboard learning for browsing Facebook, email and presenting posts on Facebook. The results indicate that learners remained neutral with the type of technology used as integration with the formal classroom. Furthermore, they added that even the learners didn't show any differences on the use of iPods for the learning. The only positive claim was made that the integration of technology has increased learners' engagement in the learning process.

Similarly, [22] established a conceptual model to investigate the aspects of the m-Learning that affect the presence of the adoption of m-Learning in Malaysian context. The findings of the study endorsed that learners perceived the usefulness of the MALL application. The gender difference didn't show any difference in the attitudes on the integration of MALL in traditional discourse. In another study [3] learners exhibited the positive perception on the use of $\mathrm{m}$ Learning. Results indicated that learners liked the idea of using MALL application as an aid with the formal classroom learning. The author in [23] explored the use of social media for learning and teaching. The findings of the study indicated that social media apps had a positive impact on the learners' performance.

The author in [24] carried out a descriptive analysis of 18 research studies on the use of laptops for the learning purposes. In the analysis of the data presented in the empirical studies, it was found that most of the studies have indicated the positive attitudes in the integration of laptops. However, researchers also indicated some challenges on the integration of technology with the traditional discourse. The author in [25] investigated the effects of $m$-Learning in fostering learners listening skill among Korean EFL undergraduate learners. The primary purpose of the study was to explore the learners' attitudes on the integration of mobile apps. The analysis of the findings indicated that most of the participants exhibited positive attitudes. On contrary the study of [26] didn't present the positive attitude towards the integration of $\mathrm{m}$-Learning. The differences in the result can be deemed by the fact that study was conducted in two different countries and cultures.

The use of m-Learning apps is still infancy and its developing. Many researchers in language learning and teaching perspective investigated the role of m-Learning apps. There is very little on the use of MALL application for science subjects and other arena of the teaching and learning. In a study carried out by [27], for illustration, indicated the participants of their experiment were, at first, mainly unaware of how smartphones could be utilized to develop and foster the process of learning but rapidly they have accepted the idea of integrating m-Learning. To sum up, learners need to be helped to indicate the advantages of m-Learning app and how to integrate and use the $\mathrm{m}$ - learning with traditional classroom discourse.

Therefore, the present study is an attempt to explore the attitudes of computer students on the use of mobile applications for learning purposes. For this purpose, following research questions were devised to gather the data for the present study:

1) Do computer students use m-Learning application for learning purposes?

2) What are the attitudes of computer students on the integration of m-Learning application in their formal learning?

\section{RESEARCH METHOdOLOGY}

The present exploratory attempt is an effort to determine the perceived use of m-Learning application among university students in the context of integration with formal classroom. The use of mobile phone is quite vibrant in daily life of the people of Saudi Arabia. Accordingly, the study is designated to focus on the exploration of learners' attitudes towards the integration of $\mathrm{m}$-Learning application in education pursuit. The study adopted the quasi-experimental design to explore the learners' attitudes. The learners were selected on the basis of their registration. The study used 3 experimental group only to investigate their attitudes on m-Learning application.

\section{A. Participants}

The participants of the present study were $(\mathrm{N}=143)$ learners who were enrolled in the second semester of the academic year 2018. All the learners were enrolled at the Preparatory Year Program where they had to study computer skills course for a period of 14 weeks. Their major was computer science and computer engineering. The age of the participants was ranging between 17 and 22 .

\section{B. Instruments}

The study used two questionnaires to collect the data for the present study. One questionnaire was administered before the experiment and the second one was distributed after 7 weeks of the study experiment. Pre-questionnaire consisted of two main parts (the use of application and the use of application for educational purposes) with responses from sometimes to rarely. The second questionnaire was based on 5-point Likert-scale questionnaire from strongly agree to strongly disagree. Both questionnaires were devised by the researcher and then sent to expert in the field of $\mathrm{m}$-Learning to check the face validity of the items. The expert suggestions were incorporated in the questionnaires. Then Google form was created to collect the responses of the participants. The reliability of the questionnaire was checked during the pilot period of the study. The reliability of the questionnaire was (.81 and .79) respectively which indicated that the instrument was reliable to gather the data. 


\section{Procedure}

On the onset of the study, learners were asked to response a questionnaire. In this questionnaire, they were asked to indicate their usage of m-Learning applications in general and for educational purposes. Based on the responses of the participants' usage of m-Learning application, WhatsApp was chosen to send and discuss the material for computer skills course. The participants were asked to do solve the one-page assignments and send them in the groups. The researcher who was also the instructor of these groups sent assignment titles in the group. Participants were asked to check the responses of other members of the groups and they were encouraged to correct the mistakes they saw in the group. The discussion was continued for 6 weeks with two times weekly exposure to the application. The material sent in the group was taken from the course. Finally, in $7^{\text {th }}$ week of the experiment, post questionnaire was sent to learners to underpin their attitudes. Their responses were transported into SPSS 22 software after coding them. The descriptive analysis was used to calculate the mean scores and standard of the responses of learners' attitudes.

\section{REsUlts}

Table I displays the participants' usage of mobile phone application in their everyday life. They were asked to choose from the given 5 applications.

Table I displays the computer students use of mobile phone application daily. It is obvious from Fig. 1 that almost all students use mobile application daily. Some of them use multiple applications. Most of the learners $(n=119,83 \%)$ use WhatsApp application for the communication and other purposes whereas Twitter $(\mathrm{n}=115,73 \%)$ and YouTube $(\mathrm{n}=115,80 \%)$ are also being used frequently.

\section{A. Computer Students' usage of Mobile Apps for Learning Purposes}

Table II given below display the computer students' use of the m-Learning application for academic purposes. For this purpose they were asked to rate the frequency (Always, Frequently, Sometimes, rarely, Never) of the usage of mLearning applications.

TABLE I. COMPUTER STUDENTS' USAGE OF MOBILE APPLICATIONS

\begin{tabular}{|l|l|l|l|}
\hline S.No & Applications & Numbers of users & Percentages \\
\hline 1 & WhatsApp & 119 & $83 \%$ \\
\hline 2 & Twitter & 105 & $73 \%$ \\
\hline 3 & Soma & 33 & $23 \%$ \\
\hline 4 & Sanpchat & 25 & $17 \%$ \\
\hline 5 & FB Messenger & 20 & $14 \%$ \\
\hline 6 & youtube & 115 & $80 \%$ \\
\hline
\end{tabular}

TABLE II. CURRENT USE OF MOBILE APPS FOR LEARNING PURPOSES

\begin{tabular}{|l|l|l|l|}
\hline S.No & Frequency & Use of apps & Percentages \\
\hline 1 & Always & 5 & $3 \%$ \\
\hline 2 & Frequently & 14 & $10 \%$ \\
\hline 3 & Sometimes & 30 & $21 \%$ \\
\hline 4 & Rarely & 43 & $30 \%$ \\
\hline 5 & Never & 61 & $43 \%$ \\
\hline
\end{tabular}

It is obvious from Table II that computer students' usage of mobile application is very low. They hardly use the mLearning applications for learning purposes. A considerable high number $(\mathrm{n}=61,43 \%)$ never used $\mathrm{m}$-Learning applications for learning purposes. This is followed by $(n=43,30 \%)$ participants had rarely used m-Learning applications. Only $21 \%$ learners used m-Learning applications for learning and $3 \%$ had exposure to m-Learning applications for learning purposes.

\section{B. Computer Students' Attitudes on the Integration of Learning Applications}

Table II illustrates the computer students' attitudes on the usage of m-Learning application as an aid with their formal classroom teaching. They were exposed to m-Learning application WhatsApp for solving assignments and discussion, which they were supposed to share in the WhatsApp group. Their responses were recorded and illustrated in the table.

TABLE III. COMPUTER STUDENTS' ATTITUDES ON THE INTEGRATION OF LEARNING APPLICATIONS

\begin{tabular}{|c|c|c|c|c|c|}
\hline m-Learning Usage & SD & $\mathrm{D}$ & $\mathrm{N}$ & $\mathrm{A}$ & SU \\
\hline $\begin{array}{l}\text { m-Learning app are beneficial for } \\
\text { my learning. }\end{array}$ & $3 \%$ & $5 \%$ & $10 \%$ & $36 \%$ & $46 \%$ \\
\hline $\begin{array}{l}\text { m-Learning have the potential of } \\
\text { group work and offer rapid } \\
\text { communication. }\end{array}$ & $4 \%$ & $7 \%$ & $11 \%$ & $41 \%$ & $47 \%$ \\
\hline $\begin{array}{l}\text { m-Learning can assist me in } \\
\text { looking for my study resources. }\end{array}$ & $2 \%$ & $6 \%$ & $13 \%$ & $30 \%$ & $49 \%$ \\
\hline $\begin{array}{l}\text { m-Learning can open many } \\
\text { opportunities to develop learning } \\
\text { process. }\end{array}$ & $3 \%$ & $7 \%$ & $8 \%$ & $32 \%$ & $50 \%$ \\
\hline $\begin{array}{l}\text { m-Learning has the ability to } \\
\text { access the study -material } \\
\text { anytime and anywhere. }\end{array}$ & $4 \%$ & $6 \%$ & $7 \%$ & $28 \%$ & $55 \%$ \\
\hline $\begin{array}{l}\text { m-Learning is an easy and quick } \\
\text { way to get instructions from the } \\
\text { teachers. }\end{array}$ & $4 \%$ & $3 \%$ & $6 \%$ & $40 \%$ & $47 \%$ \\
\hline $\begin{array}{l}\text { m-Learning is a good tool of } \\
\text { sharing study-material with } \\
\text { classmates. }\end{array}$ & $2 \%$ & $5 \%$ & $10 \%$ & $39 \%$ & $44 \%$ \\
\hline $\begin{array}{l}\text { m-Learning apps have helped me } \\
\text { to manage my learning } \\
\text { effectively. }\end{array}$ & $7 \%$ & $10 \%$ & $5 \%$ & $30 \%$ & $48 \%$ \\
\hline $\begin{array}{l}\text { m-Learning had the potential to } \\
\text { do the home homework and } \\
\text { classwork. }\end{array}$ & $10 \%$ & $8 \%$ & $11 \%$ & $28 \%$ & $43 \%$ \\
\hline $\begin{array}{l}\text { m-Learning can assist me to } \\
\text { foster learning skills. }\end{array}$ & $9 \%$ & $7 \%$ & $12 \%$ & $40 \%$ & $32 \%$ \\
\hline $\begin{array}{l}\text { m-Learning is a good source of } \\
\text { interaction with the teachers. }\end{array}$ & $2 \%$ & $6 \%$ & $8 \%$ & $45 \%$ & $39 \%$ \\
\hline $\begin{array}{l}\text { m-Learning is useful for } \\
\text { feedback from classmates and } \\
\text { instructors. }\end{array}$ & $8 \%$ & $5 \%$ & $7 \%$ & $31 \%$ & $49 \%$ \\
\hline $\begin{array}{l}\text { m-Learning increased my group } \\
\text { discussion. }\end{array}$ & $2 \%$ & $8 \%$ & $6 \%$ & $42 \%$ & 42 \\
\hline $\begin{array}{l}\text { I will continue using m-Learning } \\
\text { applications for learning other } \\
\text { subjects }\end{array}$ & $3 \%$ & $5 \%$ & $4 \%$ & $38 \%$ & $51 \%$ \\
\hline m-Learning causes distraction. & $50 \%$ & $29 \%$ & $10 \%$ & $7 \%$ & $4 \%$ \\
\hline
\end{tabular}


Table III presents the learners' attitudes on the integration of m-leaning applications. It is viable from the results that learners acknowledged the idea of using m-Learning application as a support in computer skills learning. A large number of participants (36\% strongly agree and 47\%) regarded $\mathrm{m}$-Learning as beneficial for the learning purposes as compared to only $3 \%$ who didn't endorse the idea. The maximum proportion (28\% agree and $55 \%$ strongly agree) of the m-Learning aspect was item no 5, where learners indicated that the m-Learning has the potential to deliver study material anywhere effectively. Moreover, it is also evident that participants showed positive attitudes on the aspect of $\mathrm{m}$ Learning. They marked that this would also be beneficial for learning other skills and subjects. As they portrayed this in item no. 10 where $40 \%$ of the participants indicated it useful for other learning other skill and $32 \%$ of the participants marked it strongly agree. This shows their positive perception on the integration of the m-Learning application.

It is also notable that a large number (38\% agree and $51 \%$ strongly agree) of participants indicated positive attitude towards the behavioral intention. This indicates their positive attitudes towards the m-Learning applications. Only a small proportion (4\% strongly agreed) of the experiment indicated that $\mathrm{m}$-Learning is source of distraction when they are used for learning purposes.

\section{DISCUSSION}

The incorporation of technology is not infancy now in the institutions, and m-Learning applications have attained a special place in teaching and learning process. The ubiquity of mobile devices allows learners to integrate it pervasively for learning purposes. Thus, it is important to recognize the effect of technology integration as an option for learning. Currently, mobile learning devices have had a great impact on the daily life, as most of the people are having modern mobile phone devices, which offer learning opportunities. These assist users to interact with other people and sometimes to the device itself. Various studies have endorsed the idea of integration of the m-Learning application for the learning purposes. The review of literatures presents that the focus of the utility of the m-Learning apps was main on the language learning and teaching.

The analysis of the data shows that most the learners had the mobile phone devices and they did not use any of these devices for the learning purposes. Some of them were even not aware of the fact that these can be used for learning purposes. However, when they were exposed to the mLearning application, they showed enthusiasm in taking part in the WhatsApp discussion. Their attitudes towards the mLearning application integration were positive and they regarded it a useful learning tool.

The findings of the present study are in the line with [20] who investigated learners' experiences and performance of the use of multimedia design. The findings endorsed that the mlearning is operative and successful for the participants and they enjoyed the m-Learning integration. Likewise, the study result of the present study also endorsed the findings of [21]. The researchers used the mobile based application and desktop-based Blackboard learning for browsing Facebook, email and presenting posts on Facebook. The results indicated that learners remained neutral with the type of technology used as integration with the formal classroom.

Similarly, [22] endorsed that learners perceived the usefulness of the MALL application. In another study [3] learners exhibited the positive perception on the use of $\mathrm{m}$ Learning. Results indicated that learners liked the idea of using MALL application as an aid with the formal classroom learning. The author in [23] explored the use of social media for learning and teaching. The findings of the study indicated that social media apps had a positive impact on the learners' performance. The positive attitudes of m-Learning in the present study endorsed the findings of the previous studies [3, $5,24,25,27]$. However, the findings of the present attempt did not establish a link with the study of [26] The findings of their study didn't present the positive attitude towards the integration of $\mathrm{m}$-Learning. The differences in the result can be deemed by the fact that study was conducted in two different countries and cultures.

\section{CONCLUSION AND IMPLICATIONS}

Mobile-based instruction is gaining popularity and this technology is attracting the attention of researchers to determine its usefulness. This is because of the wide spectrum of its positive and useful traits like ubiquity, flexibility and connectivity. The reviewed literature showed that most of the researchers have focused on the integration of $\mathrm{m}$-Learning application in teaching language skills or other language related aspects. There is lack of literature that presents the effectiveness of m-Learning applications for computer students. This constructs the need of an investigation to gauge the learners' attitudes and effectiveness of m-Learning applications. The findings of the data analysis indicated that participants showed positive attitudes towards the integrationlearning applications. The use of m-Learning application attracted their attention.

The results indicated that the integration of m-Learning application could be very handy for the computer students. This asserts that the m-Learning application can be beneficial for other subjects. Instructor need to integrate with sending and receiving assignments and homework. Moreover, mLearning can also be utilized to evaluate the learners' performance. With less effort, teachers can get the desired results. Like many other studies, this study has some limitations. The study is limited to on male learners; a study is operational to compare the gender differences and performances of male and female learners. The present study is also limited to only one university a comparison can be made with other university locations. Finally, a comparison with other subjects is also necessary to measure the effectiveness of m-Learning application.

\section{REFERENCES}

[1] Cairo, J., Reading comprehension on the Internet: Expanding our understanding of reading comprehension to encompass new literecies. The Reading Teacher, 2003. 56(5): p. 458-464.

[2] Qian, Y., Technology-Enabled Innovation for Academic Transformation in Higher Education, in Technology Leadership for Innovation in Higher Education. 2019, IGI Global. p. 132-164. 
[3] Khan, R.M.I., et al., EFL Instructors' Perceptions on the Integration and Implementation of MALL in EFL Classes. International Journal of Language Education and Applied Linguistics, 2018: p. 39-50.

[4] Kizza, J.M., Evolving Realities: Ethical and Secure Computing in the New Technological Spaces, in Ethical and Secure Computing. 2019, Springer. p. 209-228.

[5] Shahbaz, M. and R.M.I. Khan, Use of mobile immersion in foreign language teaching to enhance target language vocabulary learning. MIER Journal of Educational Studies, Trends and Practices, 2017. 7(1).

[6] Taj, I.H., et al., Impact of Mobile Assisted Language Learning (MALL) on EFL: A meta-analysis. Advances in Language and Literary Studies, 2016. 7(2): p. 76-83.

[7] Clark, R.C. and R.E. Mayer, E-learning and the science of instruction: Proven guidelines for consumers and designers of multimedia learning. 2016: John Wiley \& Sons.

[8] Burbules, N., Watch IT: The risks and promises of information technologies for education. 2018: Routledge.

[9] Huda, M., et al., Innovative teaching in higher education: the big data approach. TOJET, 2016.

[10] Zabit, M.N.M., Problem-Based Learning on Students' Critical Thinking Skills in Teaching Business Education in Malaysia: A Literature Review. American Journal of Business Education, 2010. 3(6): p. 19-32.

[11] Zmuda, A., Breaking free from myths about teaching and learning: Innovation as an engine for student success. 2010: ASCD.

[12] Guri-Rosenblit, S. and B. Gros, E-learning: Confusing terminology, research gaps and inherent challenges. International Journal of ELearning \& Distance Education/Revue internationale du e-learning et la formation à distance, 2011. 25(1).

[13] Idrus, R.M., Mobile learning in distance education: SMS application in a physics course. Mobile learning: Malaysian initiatives and research findings. Malaysia: Centre for Academic Advancement, Universiti Kebangsaan Malaysia, 2013.

[14] Sharples, M., et al., Mobile learning, in Technology-enhanced learning. 2009, Springer. p. 233-249.

[15] Suki, N.M. and N.M. Suki, Using Mobile Device for Learning: From Students' Perspective. Online Submission, 2011.
[16] Koole, M., J. Letkeman McQuilkin, and M. Ally, Mobile learning in distance education: Utility or futility. 2010.

[17] Laurillard, D., Rethinking university teaching: A conversational framework for the effective use of learning technologies. 2002: Routledge.

[18] Burston, J., MALL: The pedagogical challenges. Computer Assisted Language Learning, 2014. 27(4): p. 344-357.

[19] Chinnery, G.M., Emerging technologies going to the MALL: Mobile assisted language learning. Language learning \& technology, 2006. 10(1): p. 9-16.

[20] Garaj, V., m-Learning in the education of multimedia technologists and designers at the university level: A user requirements study. IEEE Transactions on Learning Technologies, 2009. 3(1): p. 24-32.

[21] Kinash, S., J. Brand, and T. Mathew, Challenging mobile learning discourse through research: student perceptions of Blackboard Mobile Learn and iPad. Australasian journal of educational technology, 2012. 28(4): p. 639-655.

[22] Tan, G.W.-H., et al., Determinants of mobile learning adoption: An empirical analysis. Journal of Computer Information Systems, 2012. 52(3): p. 82-91.

[23] Gikas, J. and M.M. Grant, Mobile computing devices in higher education: Student perspectives on learning with cellphones, smartphones \& social media. The Internet and Higher Education, 2013. 19: p. $18-26$.

[24] Fleischer, H., What is our current understanding of one-to-one computer projects: A systematic narrative research review. Educational Research Review, 2012. 7(2): p. 107-122.

[25] Nah, K.C., P. White, and R. Sussex, The potential of using a mobile phone to access the Internet for learning EFL listening skills within a Korean context. ReCALL, 2008. 20(3): p. 331-347.

[26] Khaddage, F. and G. Knezek. iLearn via mobile technology: A comparison of mobile learning attitudes among university students in two nations. in 2013 IEEE 13th International Conference on Advanced Learning Technologies. 2013. IEEE.

[27] Woodcock, B., A. Middleton, and A. Nortcliffe, Considering the Smartphone Learner: an investigation into student interest in the use of personal technology to enhance their learning. Student Engagement and Experience Journal, 2012. 1(1): p. 1-15. 